\title{
Intercomparison of spanish advanced lidars in the framework of EARLINET
}

\author{
M. Sicard ${ }^{\mathrm{a}}$, M. N. Md \\ Reba, F. Rocadenbosch, \\ E. Gregorio ${ }^{\mathrm{b}}$, D. Kumar, \\ S. Tomàs, A. Comerón \\ Dept. of Signal Theory and \\ Communications, Remote \\ Sensing Lab. (RSLAB) \\ Universitat Politènica de \\ Catalunya (UPC) \\ Barcelona, Spain
}

\author{
F. Molero, M. Pujadas \\ Centro de Investigaciones \\ Energéticas, \\ Medioambientales y \\ Tecnológicas (CIEMAT) \\ Madrid, Spain
}

\author{
J. L. Guerrero-Rascado, \\ L. Alados-Arboledas \\ Dept. of Applied Physiscs, \\ Facultad de Ciencias \\ Universidad de Granada \\ Granada, Spain
}

\author{
R. Pedros, J. A. Martínez \\ Dept. of Thermodynamics, \\ Facultat de Fisica \\ Universitat de Valencia \\ Valencia, Spain
}

\begin{abstract}
To extend and reinforce the action of the EARLINETASOS project, a nucleus of Spanish advanced lidars was created. Four systems were intercompared satisfactorily in terms of backscatter coefficients at two elastic wavelengths.
\end{abstract}

Keywords: aerosols; lidar network; instrument intercomparison

\section{INTRODUCTION}

Active instruments such as lidars provide detailed information on the aerosol space distribution throughout the observation line of sight at day or nighttime. Satellite-based lidars (GLAS, on board of ICESAT (2003), CALIOP, on board of CALIPSO (2006)) offer a global cover but with revisit times on the order of ten days. Coordinated terrestrial lidar networks offer simultaneously the temporal and vertical high resolution of each individual instruments and the space sampling of an extensive geographic zone.

EARLINET (European aerosol research lidar network to establish an aerosol climatology) [1] was created in May 2000 within a project from the Fifth Framework Programme (FP) of the European Union (EU). The network started with 19 stations and is currently totalizing 27. Since March 2006 it is endorsed by the coordinated action EARLINET-ASOS from the Sixth FP of the EU. The main objective of EARLINETASOS is to improve the EARLINET infrastructure resulting in a better spatial and temporal coverage of the observations, continuous quality control for the complete observation system, and fast availability of standardized data products.

The lidars from EARLINET present a great variety of characteristics [2] and one of the specific objectives of EARLINET-ASOS is to optimize instruments and define advanced lidars able to operate unattended and to acquire enough data so as to retrieve range-resolved aerosol optical and microphysical parameters. To concentrate their efforts on this specific objective, the spanish lidar community created a spanish advanced lidar network. The first goal of this network is to perform an intercomparison of instruments and check the results against EARLINET quality control tolerances.

\footnotetext{
${ }^{\mathrm{a}}$ Corresponding author: msicard@tsc.upc.edu

${ }^{\mathrm{b}}$ Now with Dept. of Electrical Engineering, Universitat Politècnica de

Catalunya (UPC), Barcelona, Spain
}

\section{THE SPANISH ADVANCED LIDAR NETWORK}

The Spanish advanced lidar network is an initiative from the three spanish groups belonging to EARLINET-ASOS aims to promote the use of lidar instruments and data among the spanish scientific community. The mains goals of the network are:

- Extend and reinforce the actions of EARLINETASOS;

- Form a nucleus for stimulating the Spanish lidar community;

- Promote the participation of new groups for improving the spatial cover of aerosol vertical measurements on the spanish territory (including Portugal).

A total of 8 research centers or universities are participating:

- Universidad Politècnica de Catalunya (Barcelona, BAR);

- Centro de Investigaciones Energéticas Medioambientales y Tecnológicas (Madrid, MAD);

- Universidad de Granada (Granada, GRA);

- Universidad de La Laguna (La Laguna, LLA);

- Instituto Nacional de Técnica Aerospacial (Santa Cruz de Tenerife, SCT);

- Universidad de Valencia (Valencia, VAL);

- Universidad de Murcia (Murcia, MUR);

- Universidad Politécnica de Cartagena (Cartagena, CAR).

The main characteristics of the instruments involved in the network are summarized in Table 1 and their geographical repartition is shown in Fig. 1. So far, only the intercomparison of the BAR, MAD, GRA and VAL systems was performed. 
TABLE I. CHARACTERISTICS OF THE LIDARS INVOLVED IN THE SPANISH ADVANCED LIDAR NETWORK

\begin{tabular}{|c|c|c|c|c|c|c|c|c|}
\hline & \multicolumn{8}{|c|}{ Lidar stations } \\
\hline$\lambda(\mathrm{nm}) / \mathrm{E}(\mathrm{mJ})$ & $B A R$ & $M A D$ & $G R A$ & $L L A$ & $S C T$ & $V A L$ & MUR & CAR \\
\hline Lidar model & laboratory & laboratory & $\begin{array}{l}\text { Raymetrics } \\
\text { LR321 }\end{array}$ & $\begin{array}{l}\text { Eridan } \\
\text { LSA-2c }\end{array}$ & $\begin{array}{l}\text { SES Inc. } \\
\text { MPL-3 }\end{array}$ & $\begin{array}{l}\text { CIMEL Electronique } \\
\text { CAML CE370-2 }\end{array}$ & laboratory & $\begin{array}{l}\text { Elight } \\
\text { UV11 }\end{array}$ \\
\hline Elastic IR 1064 & $\mathrm{X} / \mathbf{1 6 0}$ & & $\mathrm{X} / \mathbf{1 1 0}$ & $\mathrm{X} / 100$ & & & $\mathrm{X} / 1000$ & \\
\hline Elastic VIS 532 & $\mathrm{X} / \mathbf{1 6 0}$ & $\mathrm{X} / \mathbf{1 0 0}$ & $\mathrm{p} / \mathrm{s}^{\mathrm{a}} / 65$ & $\mathrm{X} / 50$ & $\mathrm{X}^{\mathrm{b}} / 0.01$ & $\mathrm{X} / 0.004$ & $\mathrm{X} / 500$ & \\
\hline Elastic UV 355 & & & $\mathrm{X} / 60$ & & & & $\mathrm{X} / 250$ & \\
\hline Elastic UV 266 & & & & & & & $\mathrm{X} / 110$ & \\
\hline Elastic UV 390-399 & & & & & & & $\mathrm{X}$ & $\mathrm{X}$ \\
\hline Elastic UV 255-290 & & & & & & & $\mathrm{X}$ & $\mathrm{X}$ \\
\hline Raman VIS 607 & $\mathbf{X}$ & $\mathbf{X}$ & & & & & $\mathrm{X}$ & \\
\hline Raman UV 387 & & & $\mathrm{X}$ & & & & $\mathrm{X}$ & \\
\hline Raman UV 407 (WV) & & & $\mathrm{X}$ & & & & $\mathrm{X}$ & \\
\hline PRF (Hz) & 10 & 20 & 10 & 10 & 2500 & 4600 & 10 & 20 \\
\hline Scanning capability & $\mathrm{X}$ & $\mathrm{X}$ & & $\mathrm{X}$ & & & $\mathrm{X}$ & $\mathrm{X}$ \\
\hline System transportable & $\mathrm{X}$ & $\mathrm{X}$ & $\mathrm{X}$ & & $\mathrm{X}$ & $\mathrm{X}$ & & $\mathrm{X}$ \\
\hline Overlap (km) & 0.25 & $\sim 0.4$ & 0.3 & $\sim 0.3$ & 1.5 & & $0.2-2$ & $\sim 0.3$ \\
\hline Max range $(\mathrm{km})$ & 50 & 15 & $60-90$ & 10 & 60 & 5 & 50 & 5 \\
\hline
\end{tabular}

b. at $523 \mathrm{~nm}$.

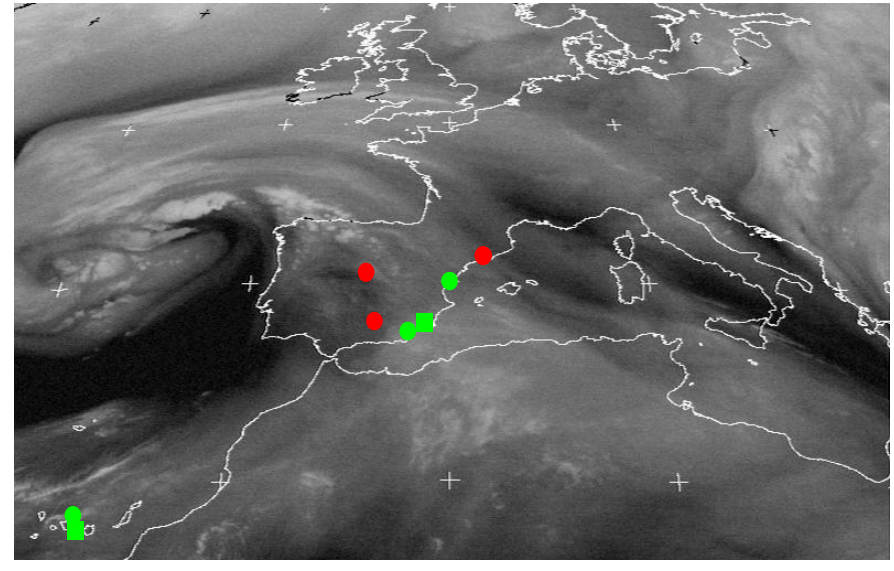

Figure 1. Geografical distribution of lidars on the Spanish territory. Circles and squares indicate transportable and untransportable systems, respectively. The red color indicates the systems belonging to EARLINET-ASOS.

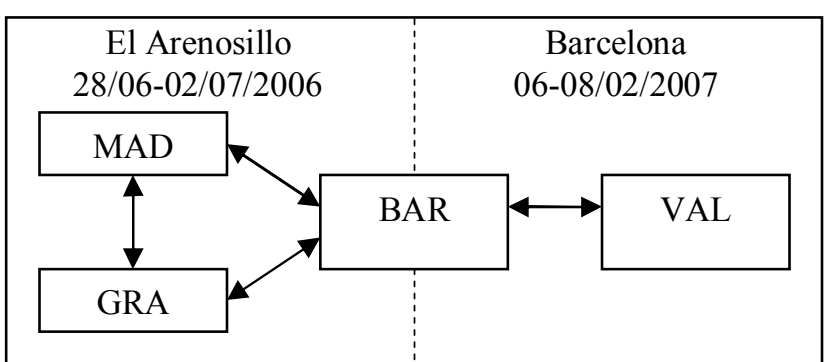

Figure 2. Diagram of intercomparison experiments.

\section{INTERCOMPARISON FIELD CAMPAIGNS}

One campaign took place in el Arenosillo (37.10N, 6.70W) in the south of Spain during 28/06-02/07/2006 and another one in Barcelona $(41.39 \mathrm{~N}, 2.11 \mathrm{E})$ during 06-08/02/2007. Fig. 2 shows the diagram of the intercomparison campaigns.

\section{A. Objectives of the intercomparisons}

The common goals of both field campaigns are:

- During the campaign, compare the range-squarecorrected profiles from different instruments pointing at the same atmospheric target to evidence differences in the pre-processing;

- After the campaign, compare quantitatively retrieved backscatter and extinction coefficients, and qualitatively the same coefficients by comparing with other types of instruments (ground and column).

\section{B. Methodology}

Diurnal cycle measurements were performed from 0800 to 2000UTC at the maximum number of elastic wavelengths possible with a 1-min. time resolution. The deliverable profiles had to be integrated over $10 \mathrm{~min}$. All the groups with Raman channels also performed nighttime measurements starting at 2130UTC with a 1-min. time resolution. The deliverable profiles were integrated over $120 \mathrm{~min}$. 


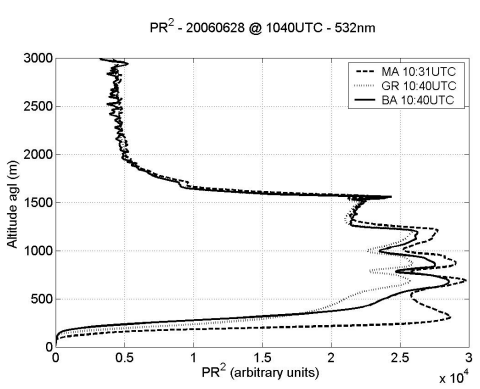

a)

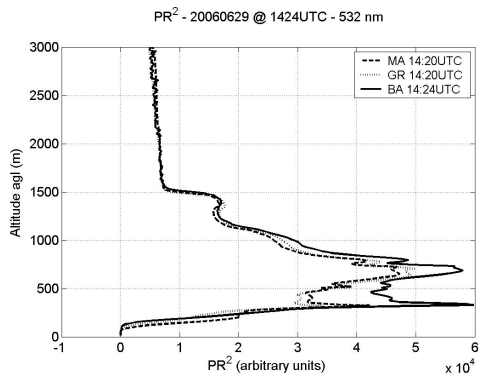

b)
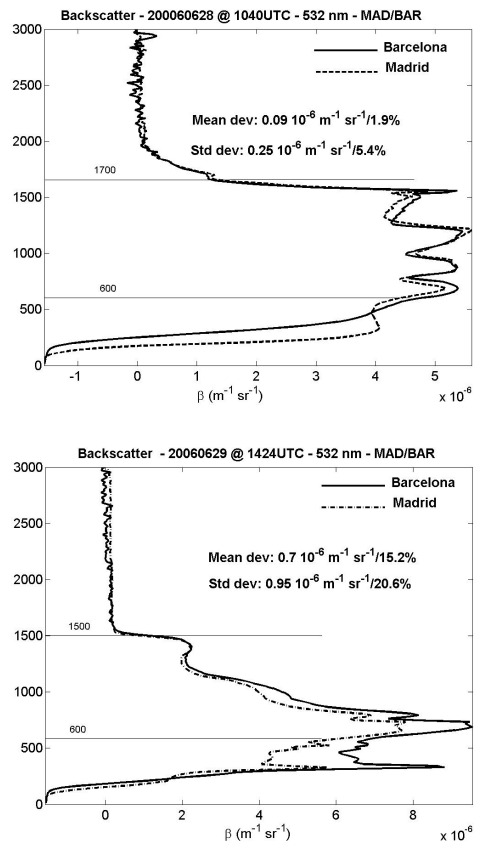

c)
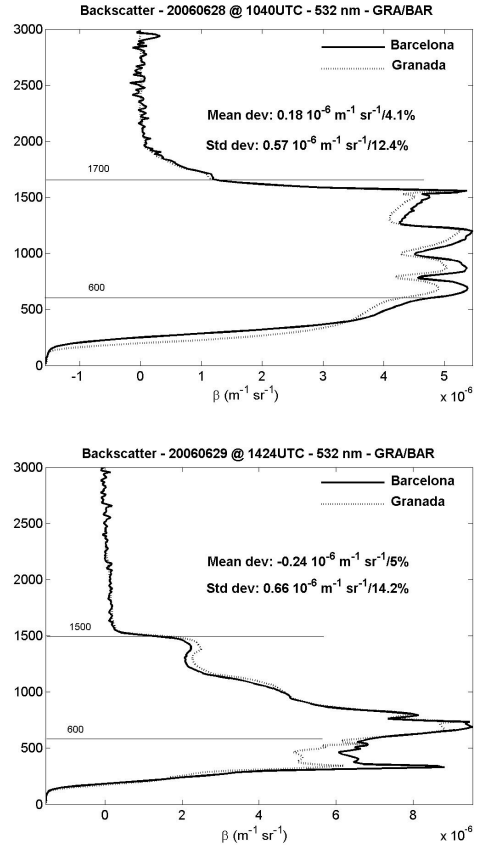

d)
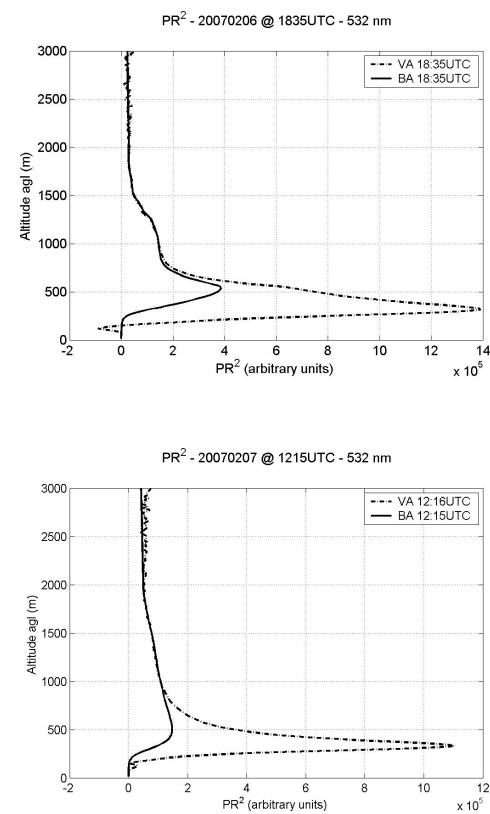

i)

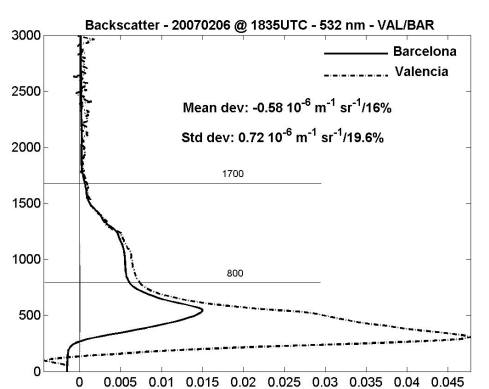

h)

j)

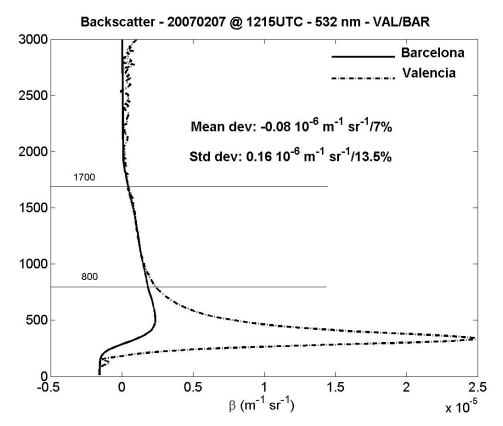

Figure 3. Intercomparison of aerosol backscatter profiles at $532 \mathrm{~nm}$ between BAR, MAD, GRA and VAL systems.

\section{RESULTS AND DisCUSSION OF THE PROBLEMS FOUND}

A total of three wavelengths $(1064,532$ and $607 \mathrm{~nm})$ were compared between the four stations (see bolt crosses in Table 1). So far only the backscatter coefficient profiles retrieved with the Klett-Fernald-Sasano method [3][4][5] were compared.

Fig. 3 shows the intercomparison of the four lidars at 532 $\mathrm{nm}$. The intercomparison of the GRA system with BAR at $1064 \mathrm{~nm}$ is shown in Fig. 4. The cases presented were chosen for the relatively high extension of the aerosol plume they present, however it was impossible to fulfil the minimum height interval condition fixed by EARLINET $(2000 \mathrm{~m})$. The results show the importance of the pre-processing optimization for all groups, and more particularly:

- the knowledge of the detectors' dynamical margins,

- the stabilization of the electronic chain,

- the overlap factor correction, 


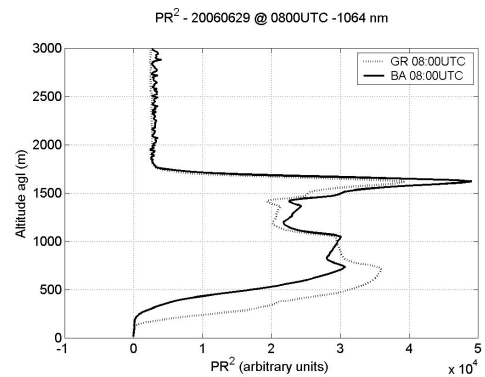

a)

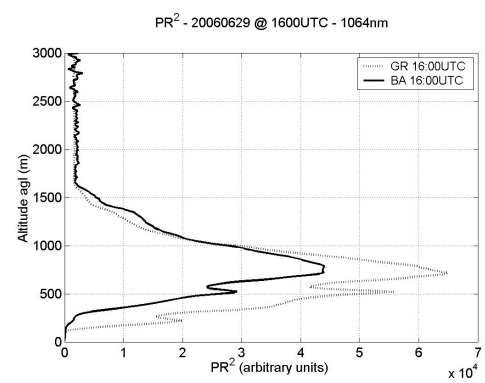

c)

Figure 4. Intercomparison of aerosol backscatter profiles at $1064 \mathrm{~nm}$ between BAR and GRA systems. b)
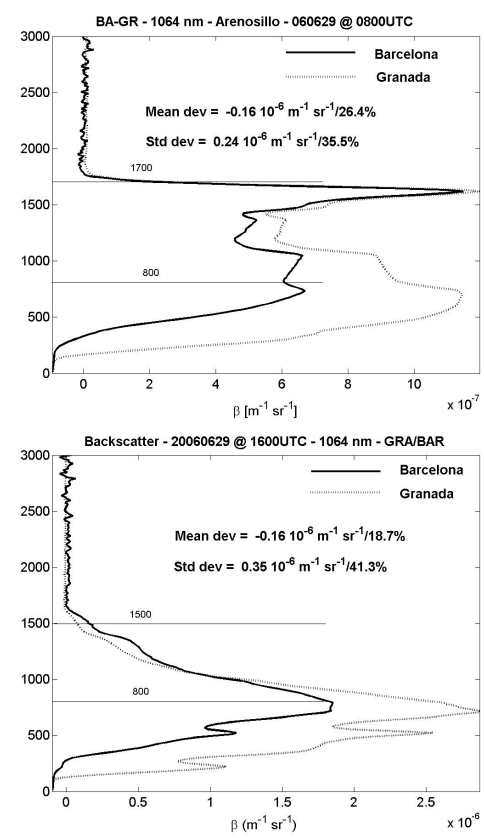

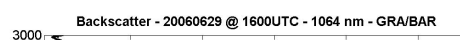

TABLE II. MEAN AND STANDARD DEVIATION OF THE INTERCOMPARISON BETWEEN BAR, MAD, GRA AND VAL SYSTEMS

\begin{tabular}{|c|c|c|c|}
\hline & $\begin{array}{l}\text { Height Range } \\
\text { (m) }\end{array}$ & $\begin{array}{l}\text { Mean dev. } \\
\left(10^{-6} \mathrm{~m}^{-1} \mathrm{~s} r^{-1}\right)\end{array}$ & $\begin{array}{l}\text { Std dev. } \\
\left(10^{-6} m^{-1} s r^{-1}\right)\end{array}$ \\
\hline BAR-MAD, $532 \mathrm{~nm}$ & & & \\
\hline 20060628@1040UTC & $600-1700$ & $0.09 / 1.9 \%$ & $0.25 / 5.4 \%$ \\
\hline $20060629 @ 1424 U T C$ & $600-1700$ & $0.7 / 15.2 \%$ & $0.95 / 20.6 \%$ \\
\hline BAR-GRA, $532 \mathrm{~nm}$ & & & \\
\hline 20060628@1040UTC & $600-1700$ & $0.18 / 4.1 \%$ & $0.57 / 12.4 \%$ \\
\hline $20060629 @ 1424 U T C$ & $600-1700$ & $-0.24 / 5 \%$ & $0.66 / 14.2 \%$ \\
\hline BAR-VAL, $532 \mathrm{~nm}$ & & & \\
\hline 20070206@1835UTC & $800-1700$ & $-0.58 / 16 \%$ & $0.72 / 19.6 \%$ \\
\hline 20070207@1215UTC & $800-1700$ & $-0.08 / 7 \%$ & $0.16 / 13.5 \%$ \\
\hline BAR-GRA, $1064 \mathrm{~nm}$ & & & \\
\hline 20060629@0800UTC & $800-1700$ & $-0.16 / 26.4 \%$ & $0.24 / 35.5 \%$ \\
\hline 20060629@1600UTC & $800-1700$ & $-0.16 / 18.7 \%$ & $0.35 / 41.3 \%$ \\
\hline
\end{tabular}

- the correct background calculation,

- the appropriate use of smoothing techniques.

They also showed that under the same atmospheric conditions the agreement between two systems at $532 \mathrm{~nm}$ is better than at $1064 \mathrm{~nm}$. Table 1 summarizes the mean and standard deviation of all 8 cases shown in Fig. 3 and 4. All of them are within EARLINET maxima (20\% for the Mean dev. and $25 \%$ for the Std. dev. at $532 \mathrm{~nm}$ and $30 \%$ for both deviations at $1064 \mathrm{~nm}$ ) except the Std. dev. at $1064 \mathrm{~nm}$. The very low value of the optical thickness $(<0.05)$ could be an explanation of the disagreement.

\section{ACKNOWLEDGMENT}

This work is supported by the European Union and FEDER funds under the EARLINET-ASOS project (EU Coordination Action, contract $n^{\circ} 025991$ (RICA)), and the project titled "Technology development programme towards a European Extremely Large Telescope" (EU Specific Support Action, contract $n^{\circ} 011863$ (RIDS)); by the MCYT (Spanish Ministry of Science and Technology) and FEDER funds under the projects TEC2006-07850/TCM and REN2003-09753-C02-02, the Complementary Actions CGL2006-27108-E/CLI, CGL2006-26149-E/CLI and CTM2006-27154-E/TECNO, and the Special Action REN2002-12784-E; and the MITYC (Spanish Ministry of Industry, Tourism and Commerce) under the PROFIT project CIT-020400-2005-56. M. Sicard is grateful to the MCYT for the Ramón y Cajal position he holds, and Md. Reba to the Local Government of Catalonia (Generalitat de Catalunya/AGAUR) for his predoctoral fellowship.

\section{REFERENCES}

[1] J. Bösenberg et al., "EARLINET: A European aerosol research lidar network", in Advances in Laser Remote Sensing of the Atmosphere, A. Dabas, C. Loth and J. Pelon, Eds., Edition Ecole Polytechnique, Palaiseau, 2001, pp. 155-158.

[2] V. Matthias et al., "Aerosol lidar intercomparison in the framework of the EARLINET project. 1. Instruments", Appl. Opt., vol. 43, 961-976, 2004.

[3] J. D. Klett, "Lidar inversion with variable backscatter/extinction ratios," Appl. Opt., vol. 24, pp. 1638-1643, 1985.

[4] F. G. Fernald, "Analysis of atmospheric lidar observations: some comments," Appl. Opt., vol. 23, 652-653, 1984.

[5] Y. Sasano and H. Nakane, "Significance of the extinction/backscatter ratio and the boundary value term in the solution for the twocomponent lidar equation,” Appl. Opt., vol. 23, 11-13, 1984. 